\title{
Relationship between Serum Elabela Level and Hypertensive Nephropathy
}

\author{
Yusuf Dogan ${ }^{1}$, Erhan Onalan ${ }^{1}$, Cundullah Cavli ${ }^{1}$, Ebru Etem Onalan ${ }^{2}$, Burkay Yakar $^{3}$ and Emir Donder ${ }^{1}$ \\ ${ }^{1}$ Department of Internal Medicine, Firat University, Medical School, Elazig, Turkey \\ ${ }^{2}$ Department of Medical Biology, Firat University, Medical School, Elazig, Turkey \\ ${ }^{3}$ Department of Family Medicine, Firat University, Medical School, Elazig, Turkey
}

\begin{abstract}
Objective: To determine the difference in serum Elabela level in hypertensive patients with and without nephropathy compared to the healthy control group.

Study Desing: Cross-sectional descriptive study.

Place and Duration of Study: Firat University Medical School, Elazig, Turkey between December 2018 and November 2020.

Methodology: The cross-sectional descriptive study consisted of 37 patients with hypertensive nephropathy (group 3), 50 hypertensive patients without nephropathy (group 2), and 50 healthy controls (group 1). Hypertensive nephropathy was defined as serum creatinine $\geq 1.8 \mathrm{mg} / \mathrm{dl}$ or GFR $<40 \mathrm{ml} /$ minute. Biochemical parameters (Glucose, AST, ALT, urea, creatinine, lipid levels, hemogram, calcium, phosphorus, parathormone) and the levels of serum Elabela were evaluated and compared.

Results: There was no significant difference in age $(0.270)$ and gender $(0.951)$ between groups. The median Elabela levels of the three groups were $40.3 \mathrm{ng} / \mathrm{mL}$ (22.5-54.6), $5.1 \mathrm{ng} / \mathrm{mL}$ (3.7-8.3), $9.2 \mathrm{ng} / \mathrm{mL}$ (6.1-23.1), respectively with a significant difference $(p<0.001)$.

Conclusion: The plasma levels of Elabela were lower in the case of hypertension, independent of nephropathy. However, this decrease is not specific for nephropathy and may be due to other accompanying chronic diseases.
\end{abstract}

Key Words: Hypertension, Hypertensive nephropathy, Elabela.

How to cite this article: Dogan Y, Onalan E, Cavli C, Onalan EE, Yakar B, Donder E. Relationship between Serum Elabela Level and Hypertensive Nephropathy. J Coll Physicians Surg Pak 2021; 31(12):1412-1416.

\section{INTRODUCTION}

Diabetes-related nephropathy and hypertensive nephropathy are among the most common causes of end-stage renal disease (ESRD). Secondary to hypertension, damage occurs in many systems causing structural and functional changes. ${ }^{1}$

Elabela, also known as Apela, is a peptide consisting of 54 amino acids. Elabela is an endogenous binder of the apelin receptor (APJ), expressed in many tissues, mainly kidney. It is secreted and circulated as a hormonal peptide in adults. ${ }^{2}$ Elabela has anti-hypertensive effects. Elabela uses the same receptoras Apelin-13, which shows hypotensive effects in both normotensive and hypertensive rats. Therefore, Elabela is thought to also regulate vascular tone. ${ }^{3}$

Correspondence to: Dr. Erhan Onalan, Erhan Onalam, Department of Internal Medicine, Firat University, Medical School, Elazig, Turkey

E-mail:drakdeniz@msn.com

Received: May 06, 2021; Revised: October 26, 2021;

Accepted: November 09, 2021

DOI: https://doi.org/10.29271/jcpsp.2021.12.1412
When Elabela was administered to the same groups of rats, blood pressure lowering activity, similar to Apelin-13, was achieved. ${ }^{4}$ Unlike Apelin, Elabela mediated vascular dilation is independent. ${ }^{5}$ Extracellular signal regulated kinase (ERK) can cause excessive vasoconstriction. ${ }^{6}$ High ERK level is blamed in the etiopathogenesis of many hypertensions, especially hypertension that develops secondary to obesity. ${ }^{7}$ Elabela has an antihypertensive effect by suppressing ERK activation. ${ }^{8}$ This relation needs to be further evaluated for clinical relevance.

The aim of this study was to determine the difference serum Elabela level in the hypertension patients with and without nephropathy compared to the healthy control group.

\section{METHODOLOGY}

This single-centre, cross-sectional descriptive study was conducted at Internal Medicine Clinic, of Fırat University Medical School, Elazig, Turkey between December 2018 and November 2020. It was designed in accordance with the ethical rules as stated in the Helsinki Declaration. Approval was obtained from the Faculty of Medicine Ethics Committee (25.10.2018, 17/02). The study group was composed of individuals between the ages of 30-75 years. Patient groups consisted of hypertensive patients with and without hypertensive nephropathy. The study group consisted of 87 patients, 37 of whom were diagnosed with 
HT and had hypertensive nephropathy, and 50 patients, who had hypertension but did not have hypertensive nephropathy. The control group was formed of 50 healthy individuals of similar age and gender, whowerenon-hypertensive, did nothave any comorbidity or lipid metabolism disorder. Individuals with a blood pressure $>130 / 80 \mathrm{mmHg}$ or using antihypertensive drugs and normal blood pressure measurements were considered hypertensive. Hypertensive patients were those with presence of longterm hypertension history with stage I / II retinopathy, failure to show other causes of kidney failure other than $\mathrm{HT}$, serum creatinine $\geq 1.8 \mathrm{mg} / \mathrm{dl}$. Individuals with GFR $40 \mathrm{ml} / \mathrm{min}$ were considered as having hypertensive nephropathy. Exclusion criteria were: under age 30 years, coexistence Diabetes mellitus, primary renal disease, non-hypertensive renal pathology, heart failure, liver disease, acute infection, hypothyroidism, malignancy and ESRD patients, who received hemodialysis or peritoneal dialysis.

The anamnesis of the individuals in the patient and control groups were taken, and their systolic and diastolic blood pressures were measured and questioned in terms of family histories. Demographic information (age, gender, body mass index values) were recorded for the entire study group. Glomerular filtration rate was calculated according to the Cockcroft-Gault Formula; as GFR = (140-age) $\times$ Body Weight $(\mathrm{kg}) / 72 \times$ Serum Creatinine $(\mathrm{mg} / \mathrm{dl})$, If female $\rightarrow \times 0.85$.

Glucose, AST, ALT, urea, creatinine, lipid levels, complete blood count, calcium, phosphorus, and Parathormone results were obtained from the records of routine examinations. Other blood samples were kept in aprotinin tubes. The blood samples taken into the tubes were centrifuged at $5000 \mathrm{rpm}$ for 5 minutes within half an hour and their serums were separated. Blood samples taken into tubes with aprotinin were stored at $-80^{\circ} \mathrm{C}$ until they were studied after centrifugation. After all samples were collected, serum Elabela levels were measured by enzyme linked-immunosorbent assay (ELISA) method. Serum Elabela levels were determined using an Elabela (human) -EIA kit (Peninsula Laboratories International, Inc., San Carlos, CA, USA) according to manufacturer's instructions. This test has inter-and intra-assay coefficients of variation below $8 \%$ and $5 \%$, respectively.

The analyses were evaluated in the SPSS versin 22 (Statistical Packagefor SocialSciences; SPSS Inc., Chicago, IL) package programme. Descriptive data in the study were shown as $n \%$ values in categorical data, and mean \pm standard deviation, median, interquartilerange (25-75 percentile values) in continuous data. Chi-square analysis (Pearson's Chi-square) was used to compare categorical variables between the groups. The suitability of continuous variables to normal distribution was evaluated with the Kolmogorov-Smirnov test. The Independent samples t-test was used for the comparison of variables conforming to the normal distribution between two groups, the Oneway ANOVA for the comparison between more than two groups, the Mann-Whitney U-test for the comparison of the variables that did not conform to the normal distribution between the two groups, and the Kruskal-Wallis test for the comparison between more than two groups. The statistical significance level in the analysis was accepted as $p<0.05$.

\section{RESULTS}

The study included 37 patients with hypertensive nephropathy, 50 patients with hypertension but no nephropathy, and 50 healthy controls. The groups were formed of similar age and gender, and no significant difference was found between the groups in terms of age and gender $(p=0.270)$. There was a significant difference between the groups in terms of height, weight and body mass index (BMI, Tablel, $p<0.05)$. It was observed that this difference for height was due to the difference between the control group and the hypertensive group and the hypertensive nephropathy group, and for weight and BMI, this difference was between the hypertensive group and the control group and the hypertensive nephropathy group. A significant difference was found between the groups in terms of systolic and diastolic blood pressure ( $p<0.001$ ). It was seen that this difference was due to the difference between the control and hypertensive groups for systolic blood pressure and the difference between the control and hypertensive nephropathy groups.

It was observed that it was caused by the difference between all groups in terms of diastolic blood pressure. No statistically significant difference was found between the hypertensive group and the hypertensive nephropathy group ( $p=0.191$, Tablel).

A significant difference was found between the groups in terms of glucose level (0.007). It was observed that this difference was between the hypertensive group and the hypertensive nephropathy group. AST and calcium levels of the hypertensive group were found to be significantly higher than the hypertensive nephropathy group ( $p<0.05$ ). Phosphorus and PTH levels in the hypertensive nephropathy group were found to be significantly higher than the hypertensive group ( $p<0.05$ ). A significant difference was found between the groups in terms of urea, creatinine and GFR ( $p<0.001$ ). It was seen that this difference was caused by the difference in all three groups. A significant difference was found between the groups in terms of hemoglobin value ( $p<0.001$ ). It was seen that this difference was due to the difference between the hypertensive nephropathy group and the hypertensive group and the control group. Finally, a significant difference was found between the groups in terms of platelet $(p=0.022)$. It was seen that this difference was caused by the hypertensive nephropathy group and the control group. No significant difference was found between the groups in terms of total cholesterol, LDL, triglyceride and ALT ( $p>0.05$, Table II).

The median Elabela level of the groups was $40.3 \mathrm{ng} / \mathrm{mL}$ (22.5-54.6) in the healthy control group, $5.1 \mathrm{ng} / \mathrm{mL}$ (3.7-8.3) in the hypertension group, and $9.2 \mathrm{ng} / \mathrm{mL}(6.1-23.1)$ in the hypertensive nephropathy group, respectively. A statistically significant difference was found between the groups $(p<0.001$, Table III). 
Table I: Comparison of the groups by age, gender, body measurements and blood pressure measurements.

\begin{tabular}{|c|c|c|c|c|c|}
\hline \multirow{2}{*}{\multicolumn{2}{|c|}{ Variables }} & \multirow{2}{*}{$\begin{array}{c}\text { Control group } \\
\begin{array}{c}\text { Median value } \\
\text { (IQR) }\end{array} \\
\end{array}$} & \multirow{2}{*}{$\begin{array}{c}\text { Hypertensive group } \\
\begin{array}{c}\text { Median value } \\
\text { (IQR) }\end{array}\end{array}$} & \multirow{2}{*}{$\begin{array}{c}\text { Hypertensive } \\
\text { nephropathy group } \\
\begin{array}{c}\text { Median value } \\
\text { (IQR) }\end{array} \\
\end{array}$} & \multirow{2}{*}{$\mathbf{p}$} \\
\hline & & & & & \\
\hline \multirow{2}{*}{ Gender. n(\%) } & Male & $24(48.0)$ & $25(50.0)$ & $19(51.4)$ & \multirow{2}{*}{$0.951^{*}$} \\
\hline & Female & $26(52.0)$ & $25(50.0)$ & $18(48.6)$ & \\
\hline \multicolumn{2}{|l|}{ Age (year) } & $59(52.75-63.25)$ & $61(49-69)$ & $65(52-69)$ & $0.270^{* *}$ \\
\hline \multicolumn{2}{|c|}{ Height $(\mathrm{m})($ Mean \pm SD) } & $1.70 \pm .1^{\mathrm{a}}$ & $1.655 \pm .1^{b}$ & $1.657 \pm .1^{\mathrm{b}}$ & $0.004^{* * *}$ \\
\hline \multicolumn{2}{|c|}{ Weight $(\mathrm{kg})($ Mean \pm SD) } & $74.1 \pm 14.2^{\mathrm{a}}$ & $81.2 \pm 13.7^{b}$ & $72.8 \pm 13.2^{\mathrm{a}}$ & $0.008^{* * *}$ \\
\hline \multicolumn{2}{|c|}{ BMI $\left(\mathrm{kg} / \mathrm{m}^{2}\right)($ Mean $\pm \mathrm{SD})$} & $25.4 \pm 3.4^{\mathrm{a}}$ & $29.8 \pm 5.5^{b}$ & $26.5 \pm 4.6^{a}$ & $<0.001^{* * *}$ \\
\hline \multicolumn{2}{|c|}{ Systolic blood pressure $(\mathrm{mmHg})$} & $120(115-125)^{a}$ & $135(130-140)^{b}$ & $140(130-150)^{b}$ & $<0.001^{* * *}$ \\
\hline \multicolumn{2}{|c|}{ Diastolic blood pressure $(\mathrm{mmHg})$} & $70(65-80)^{a}$ & $80(80-90)^{b}$ & $90(80-90)^{c}$ & $<0.001^{* * *}$ \\
\hline \multicolumn{2}{|c|}{ Disease duration (years) } & - & $6(2-10)$ & $10(3-15)$ & $0.191^{* * * *}$ \\
\hline
\end{tabular}

Table II: Comparison of blood values of groups.

\begin{tabular}{|c|c|c|c|c|}
\hline \multirow[b]{2}{*}{ Variables } & Control group & Hypertensive group & Hypertensive nephropathy group & \multirow[b]{2}{*}{$\mathbf{p}$} \\
\hline & $\begin{array}{c}\text { Median value } \\
\text { (IQR) }\end{array}$ & $\begin{array}{c}\text { Median value } \\
\text { (IQR) }\end{array}$ & $\begin{array}{c}\text { Median value } \\
\text { (IQR) }\end{array}$ & \\
\hline T. Cholesterol (mg/dl) (Mean \pm SD) & $172.5 \pm 30.0$ & $180.4 \pm 45.6$ & $180.4 \pm 44.7$ & $0.545^{*}$ \\
\hline LDL (mg/dl) (Mean $\pm S D)$ & $100.6 \pm 25.5$ & $114.4 \pm 34.6$ & $108.8 \pm 30.5$ & $0.077^{*}$ \\
\hline TG (mg/dl) & - & $132.0(100.0-157.0)$ & $126.0(105.0-157.0)$ & $0.850^{* *}$ \\
\hline Glucose (mg/dl) (Mean \pm SD) & $90.3 \pm 10.2^{a . b}$ & $95.2 \pm 12.0^{\mathrm{a}}$ & $87.6 \pm 12.1^{b}$ & $0.007^{*}$ \\
\hline AST (mg/dl) & - & $23.0(19.0-26.0)$ & $18.0(16.0-20.0)$ & $<0.001^{* *}$ \\
\hline $\mathrm{ALT}(\mathrm{mg} / \mathrm{dl})$ & - & $19.0(13.0-27.0)$ & $16.0(12.0-20.0)$ & $0.086^{* *}$ \\
\hline Urea (mg/dl) & $26.0(22.0-31.0)^{\mathrm{a}}$ & $38.0(29.0-51.0)^{b}$ & $107.0(78.0-141.0)^{c}$ & $<0.001^{* * *}$ \\
\hline Creatinine (mg/dl) & $.7(.6-.9)^{\mathrm{a}}$ & $.9(.7-1.1)^{b}$ & $2.9(2.4-4.0)^{c}$ & $<0.001^{* * *}$ \\
\hline Calcium (mg/dl) & - & $9.0(8.8-9.4)$ & $8.7(8.3-9.4)$ & $0.021^{* *}$ \\
\hline Phosphorus (mg/dl) & - & $3.6(3.1-4.0)$ & $4.0(3.2-4.8)$ & $0.023^{* *}$ \\
\hline GFR (ml/dk) & $134.6(123.3-146.3)^{a}$ & $90.5(67.1-125.4)^{b}$ & $23.9(17.7-31.0)^{c}$ & $<0.001^{* * *}$ \\
\hline $\mathrm{Hgb}(\mathrm{g} / \mathrm{dl})($ Mean $\pm \mathrm{SD})$ & $14.0 \pm 1.4^{\mathrm{a}}$ & $13.7 \pm 1.7^{\mathrm{a}}$ & $11.5 \pm 2.4^{b}$ & $<0.001^{*}$ \\
\hline PLT $(* 1000 / \mu l)($ Mean \pm SD) & $270.4 \pm 64.4^{\mathrm{a}}$ & $258.7 \pm 67.7^{a . b}$ & $224.9 \pm 98.8^{b}$ & $0.022^{*}$ \\
\hline PTH (pg/ml) & - & $66.8(51.0-104.0)$ & $206.6(147.2-375.7)$ & $<0.001^{* *}$ \\
\hline
\end{tabular}

Table III: Comparison of elabela level according to groups.

\begin{tabular}{|l|c|c|c|c|}
\hline \multirow{2}{*}{ Variables } & Control group & Hypertensive group & Hypertensive nephropathy group \\
\cline { 2 - 5 } & $\begin{array}{c}\text { Median value } \\
\text { (IQR) }\end{array}$ & $\begin{array}{c}\text { Median value } \\
\text { (IQR) }\end{array}$ & $\begin{array}{c}\text { Median value } \\
\text { (IQR) }\end{array}$ & $\mathbf{p}^{2}$ \\
\hline Elabela & $40.3(22.5-54.6)^{\mathrm{a}}$ & $5.1(3.7-8.3)^{\mathrm{b}}$ & $(6.1-23.1)^{\mathrm{c}}$ \\
\hline
\end{tabular}

\section{DISCUSSION}

Hypertension is the major contributing factor to all-cause mortality. It is the main risk factor for stroke (ischemic and hemorrhagic) and coronary artery disease. Moreover, people with hypertension are predisposed to kidney failure, heart failure, peripheral vascular disease, and other medical conditions. It is estimated that around 1.4 billion adults worldwide have hypertension. ${ }^{9}$ Hypertension is the second most common cause of ESRD. ESRD developed due to hypertensive nephropathy in $30 \%$ of all patients receiving renal replacement therapy. ${ }^{10}$
Elabela, which has many forms, has the highest isoform among vertebrate species, Elabela-11. ${ }^{11}$ Elabela, which has a high rate in the endothelial structure of the heart and arteries, provides benefits by increasing the contraction of the heart and providing coronary vasodilation. ${ }^{12,13}$ Elabela improves heart function by reducing angiotensin converting enzyme (ACE) expression in the heart during stress. ${ }^{14}$ Elabela injection in rats increases diuresis. ${ }^{15}$ In addition, elabela is required for mouse embryonic angiogenesis. ${ }^{16}$

There are many studies in the literature regarding the function of Elabela and its level in various diseases. In this study, the authors investigated the levels of Elabela in the healthy 
group, hypertensive group and hypertensive nephropathy group.

Li et al found that the level of Elabela decreased significantly in hypertensive patients compared to healthy individuals ( $p$ $=0.001)^{17}$

In this study, serum Elabela levels of 50 hypertensive patients who were similar in age and had a significant difference in blood pressure and 50 patients in the control group were examined. Similar to the study by Li et al., serum Elabela level was found to be lower in the hypertensive group with statistical significance.

Chen et al. studied ischemia reperfusion injury, one of the causes of acute kidney injury, in mice. Elabela mRNA levels were examined in mice injured by ischemia reperfusion and it was observed that it decreased in nephropathy. ${ }^{18}$ In this study, it was found that Elabela was at a statistically lower level in the group with hypertensive nephropathy compared to healthy individuals.

In the study by Xu et al. using Anti-ELA antibodies, it was determined that Elabela was mostly found in the apical membrane of the epithelial cells of the collecting tubule. ${ }^{19}$ In the same study, salt-sensitive mice were compared with salt-resistant mice. Less apela secretion was observed in the medulla of salt-sensitive mice after the administration of large amounts of salt. Administration of ELA-32 in salt-sensitive mice suppresses hypertension, fibrosis, and inflammation caused by high amounts of salt administration. ${ }^{19}$ Again, in this study, blood pressure was measured by radiotelemetry in salt sensitive mice after high salt diet. Exogenous ELA-32 infusion has been shown to significantly suppress hypertension caused by excessive salt administration in salt-sensitive mice. ${ }^{19}$

This study, in which Elabela was found low in nephropathy, supports the study of Xu. et al. They detected high amounts of Elabela in the renal collecting tubules by RNA scope and immunofluorescence methods. Similarly, low Elabela in hypertension may indicate that Elabela has protective effects on hypertension.

Zhang et al. reported that serum Elabela level decreased with the increase of diabetic kidney damage and serum Elabela level had a positive correlation with GFR. ${ }^{20}$ They also experimented on mice, on the basis that Elabela may have a protective role in diabetic nephropathy. Injections of Elabela were administered after diabetes was established in mice. As a result, they found that kidney fibrosis and renal inflammation were reduced, and kidney damage was improved. ${ }^{21}$ In this study, Elebela level was found to be lower in the healthy group compared to the hypertension and hypertensive nephropathy group. This result leads to the conclusion that Elabela may decrease with kidney damage or decrease in Elabela level may cause kidney damage. The fact that
Elabela is low in conditions such as hypertension and nephropathy and that exogenous Elabela application improves existing pathology in other studies shows the positive effects of Elabela on these systems.

The most important limitations of this study are that it is a single-centre study and the number of patients is low.

\section{CONCLUSION}

In this study, the level of Elabela were decreased in hypertensive nephropathy, is consistent with the studies in the current literature. However, these findings should be supported by large-scale studies conducted in several different centres.

\section{ETHICAL APPROVAL:}

The study protocol was approved by the Ethics Committee of Firat University (No. 17-02, Date: 25.10.2018). The study was conducted in accordance with the principles of the Declaration of Helsinki.

\section{PATIENTS' CONSENT:}

Written informed consents were obtained from all patients.

\section{CONFLICT OF INTEREST:}

The authors declared no conflict of interest.

\section{AUTHORS' CONTRIBUTION:}

YD, EO: Data collection, design, compiling, and discussion, Led and conceived the project, and authored the manuscript.

CC: Data collection, design.

EEO: Study of biochemical data.

BY: Collecting and analysing data, discussion.

ED: Collecting, statistics and analysing data.

\section{REFERENCES}

1. Devereux RB, Alderman MH. Role of preclinical cardiovascular disease in the evolution from risk factor exposure to development of morbid events. Circulation 1993; 88(4 Pt 1): 1444-55. doi: 10.1161/01.cir.88.4.1444.

2. Pauli A, Norris ML, Valen E, Chew GL, Gagnon JA, Zimmerman S, et al. Toddler: An embryonic signal that promotes cell movement via Apelin receptors. Science 2014; 343(6172):1248636. doi: 10.1126/science.1248636.

3. Wang Z, Yu D, Wang M, Wang Q, Kouznetsova J, Yang R, et al. Elabela-apelin receptor signaling pathway is functional in mammalian systems. Sci Rep 2015; 5:8170. doi: 10.1038/srep08170.

4. Helker CS, Schuermann A, Pollmann C, Chng SC, Kiefer F, Reversade $B$, et al. The hormonal peptide Elabela guides angioblasts to the midline during vasculogenesis. eLife 2015; 4:e06726. doi: 10.7554/eLife.06726.

5. Touyz RM, He G, El Mabrouk M, Diep Q, Mardigyan V, Schiffrin EL. Differential activation of extracellular signal-regulated protein kinase $1 / 2$ and p38 mitogen activated-protein kinase by AT1 receptors in vascular smooth muscle cells from Wistar-Kyoto rats and spontaneously hypertensive 
rats. J Hypertension 2001; 19(3 Pt 2):553-9. doi: 10.1097/ 00004872-200103001-00006.

6. Watts SW. 5-Hydroxytryptamine-induced potentiation of endothelin-1- and norepinephrine-induced contraction is mitogen-activated protein kinase pathway dependent. Hypertension 2000; 35(1 Pt 2):244-8. doi: 10.1161/ 01.hyp.35.1.244.

7. Banday AA, Fazili FR, Marwaha A, Lokhandwala MF. Mitogen-activated protein kinase upregulation reduces renal D1 receptor affinity and G-protein coupling in obese rats. Kidney Int 2007; 71(5):397-406. doi: 10.1038/sj.ki.5002055.

8. Schreiber CA, Holditch SJ, Generous A, Ikeda Y. Sustained elabela gene therapy in high salt-ınduced hypertensive rats. Curr Gene Ther 2017; 16(5):349-60. doi: 10.2174/ 1566523217666161121111906.

9. Mills KT, Bundy JD, Kelly TN, Reed JE, Kearney PM, Reynolds $K$, et al. Global disparities of hypertension prevalence and control: a systematic analysis of population-based studies from 90 countries. Circulation 2016; 134(6):441-50. doi: 10.1161/CIRCULATIONAHA.115.018912.

10. Schlessinger SD, Tankersley MR, Curtis JJ. Clinical documentation of end-stage renal disease due to hypertension. $\mathrm{Am} \mathrm{J}$ Kidney Dis 1994; 23(5):655-60. doi: 10.1016/s02726386(12)70275-5.

11. Huang SK, Shin K, Sarker M, Rainey JK. Apela exhibits isoformand headgroup-dependent modulation of micelle binding, peptide conformation and dynamics. Biochim Biophys Acta 2017; 1859(5):767-78. doi: 10.1016/j.bbamem.2017. 01.028 .

12. Perjes A, Kilpio T, Ulvila J, Magga J, Alakoski T, Szabo Z, et al. Characterisation of apela, a novel endogenous ligand of apelin receptor, in the adult heart. Basic Res Cardiol 2016; 111(1):2. doi: 10.1007/s00395-015-0521-6.

13. Yang P, Read C, Kuc RE, Buonincontri G, Southwood M, Torella $\mathrm{R}$, et al. Elabela/Toddler Is an endogenous agonist of the apelin apj receptor in the adult cardiovascular system, and exogenous administration of the peptide compensates for the downregulation of its expression in pulmonary arte- rial hypertension. Circulation 2017; 135(12):1160-73. doi: 10.1161/CIRCULATIONAHA.116.023218.

14. Sato T, Sato C, Kadowaki A, Watanabe H, Ho L, Ishida J, et al. ELABELA-APJ axis protects from pressure overload heart failure and angiotensin II-induced cardiac damage. Cardiovasc Res 2017; 113(7):760-9. doi: 10.1093/cvr/cvx061.

15. Deng C, Chen H, Yang N, Feng Y, Hsueh AJ. Apela regulates fluid homeostasis by binding to the APJ receptor to activate Gi signaling. J Biol Chem 2015; 290(30):18261-8. doi: 10.1074/jbc.M115.648238.

16. Ho L, van Dijk M, Chye STJ, Messerschmidt DM, Chng SC, Ong $\mathrm{S}$, et al. ELABELA deficiency promotes preeclampsia and cardiovascular malformations in mice. Science 2017; 357(6352):707-13. doi: 10. 1126/science.aam6607.

17. Li Y, Yang X, Ouyang S, He J, Yu B, Lin X, et al. Declined circulating elabela levels in patients with essential hypertension and its association with impaired vascular function: A preliminary study. Clin Exp Hypertens 2020; 42(3):1-5. doi: 10.1080/10641963.2019.1619756.

18. Chen H, Wang L, Wang W, Cheng C, Zhang Y, Zhou Y, et al. ELABELA and an ELABELA fragment protect against AKI. J Am Soc Nephrol 2017; 28(29):2694-2707. doi: 10.1681/ASN.2016111210.

19. Xu C, Wang F, Chen Y, Xie S, Sng D, Reversade B, et al. ELABELA antagonizes intrarenal renin-angiotensin system to lower blood pressure and protects against renal injury. Am J Physiol Renal Physiol 2020; 318(5):F1122-F35. doi:10. 1152/ajprenal.00606.2019.

20. Zhang H, Gong D, Ni L, Shi L, Xu W, Shi M, et al. Serum Elabela/ Toddler levels are associated with albuminuria in patients with type 2 diabetes. Cell Physiol Biochem 2018; 48(3):1347-54. doi: 10.1159/000492093.

21. Zhang Y, Wang Y, Luo M, Xu F, Lu Y, Zhou X, et al. Elabela protects against podocyte injury in mice with streptozocin-induced diabetes by associating with the PI3K/Akt/mTOR pathway. Peptides 2019; 114: 29-37. doi: 10.1016/j.peptides.2019.04.005. 